\title{
AMORIS LAETITIA: UN ETHOS PASTORAL *
}

\author{
Amoris laetitia: a Pastoral Ethos
}

Tony Mifsud **

RESUMEN: El artículo comienza haciendo memoria del proceso sinodal que condujo a la elaboración de la exhortación apostólica Amoris laetitia, pasando, en un segundo momento, a recordar las distracciones y críticas que recibió por parte de un grupo, pequeño pero vociferante. En una tercera sección, se reflexiona sobre la evolución disciplinar, destacando la relación existente entre la experiencia de la fe y el compromiso de la ética, como también la importancia de una ética capaz de asumir la realidad y dirigirla hacia el ideal cristiano. La gran contribución de Amoris laetitia, en el campo de la Teología Moral, es haber fundamentado oficialmente un ethos de acompañamiento que respeta la adultez del auténtico cristiano.

PALABRAS-CLAVES: Matrimonio. Divorciados vueltos a casar. Pastoral. Ética y Moral. Misericordia y Fidelidad.

ABSTRACT: The article begins by recalling the synodal process that led to the development of the apostolic exhortation Amoris laetitia. Next, it recalls the distractions and criticisms it received from a small but vociferous group. The third section reflects on disciplinary evolution, highlighting the relationship between the experience of faith and the commitment to ethics, as well as the importance of an ethics capable of assuming reality and directing it towards the Christian ideal. The great contribution of Amoris laetitia, in the field of Moral Theology, is to have officially founded an ethos of accompaniment that respects the adulthood of the authentic Christian.

KEYWORDS: Marriage. Divorced remarried. Pastoral. Morals and ethics. Mercy and Fidelity.

\footnotetext{
* Este artículo es un desdoblamiento del texto "La alegría del amor", publicado en la revista Mensaje, Chile, 65 (648), p. 6 - 10, 2016.

** Universidad Católica del Norte, Antofagasta, Chile.
} 
D espués de dos años de trabajo sinodal y una amplia participación de los fieles a nivel mundial, el Papa Francisco publicó su exhortación postsinodal el día 8 de abril de 2016, aunque con fecha del 19 de marzo, sobre la familia con el título de La alegría del amor (Amoris laetitia - AL). El documento contiene 325 párrafos y está dividido en nueve capítulos, comenzando con una descripción de la situación de la familia en el mundo contemporáneo, pasando a revisar la enseñanza oficial de la Iglesia al respecto y profundizando en el lugar del amor en la vida matrimonial, para animar a una renovada pastoral familiar y se termina con una reflexión sobre las situaciones especiales en el ámbito del matrimonio.

La palabra alegría, en términos de gozo, aparecerá dos años más tarde en la exhortación apostólica Gaudete et exsultate (19 de marzo de 2018) sobre la llamada a la santidad en el mundo contemporáneo. El tema de la alegría es recurrente en el pensamiento del Papa Francisco. No se trata de una palabra de paso sino de una convicción profunda. De hecho, en su Discurso a los miembros de la 36 Congregación General de la Compañía de Jesús, (24 de octubre de 2016), afirma que "la alegría es constitutiva del mensaje evangélico... Una buena noticia no se puede dar con cara triste. La alegría no es un plus decorativo, es índice claro de la gracia: indica que el amor está activo, operante y presente".

\section{Preparación y publicación}

El quinto aniversario de la exhortación postsinodal del Papa Francisco es una oportunidad para poder apreciar su gran contribución pastoral, lamentablemente no aprovechada adecuadamente, especialmente en el campo de la ética teológica. La distancia permite alejarse del ambiente polémico que surgió a la hora de su publicación y realizar una reflexión más serena y objetiva.

\subsection{El camino sinodal}

El nuevo estilo del Papa Francisco se dejó entrever en la fase de la preparación del documento. El proceso sinodal comienza en el mes de noviembre del año 2013, cuando se envía un documento preparatorio con un amplio cuestionario dirigido a los fieles y las iglesias locales. Este primer documento sustituyó el tradicional Lineamenta preparado en el Vaticano para poder escuchar e involucrar al pueblo de Dios.

Este texto, que recogía el parecer de las iglesias locales dispersas por todo el mundo, fue la base del primer Sínodo Extraordinario celebrado entre el 5 y el 9 de octubre de 2014. Al final de este Sínodo Extraordinario se 
elaboró un Relatio Synodi. El siguiente año, 4 al 25 de octubre de 2015, se realiza el Sínodo Ordinario, concluyendo con el Relatio finalis.

La Relación final fue aprobada íntegramente por una mayoría de los dos tercios de los Padres sinodales (por primera vez se dio a conocer la votación que recibió cada párrafo del texto) y fue la base de la exhortación apostólica del Papa Francisco. Al respecto, conviene señalar un detalle importante: en este sentido, la exhortación pontificia refleja el pensamiento episcopal de la mayoría presente en el Sínodo y, por tanto, no sólo del Papa Francisco. Así, se encuentra presente una eclesiología de comunión y un camino sinodal. (SPADARO, 2016, p. 108).

De hecho, el Papa Francisco ejerce la colegialidad episcopal no sólo mediante la referencia constante a la Relación final, sino también a las Conferencias Episcopales: Argentina, Australia, Colombia, Corea, Chile, España, Italia, Kenia y México.

La exhortación apostólica AL es una expresión de una Iglesia en salida porque dialoga con la sociedad moderna. En primer lugar, porque tiene un lenguaje comprensible. Además, y probablemente por primera vez, se hace referencia a una película en un documento pontificio (n.129). Concretamente, la película danesa La fiesta de Babette (Director Gabriel Axel, 1987), ganadora del Oscar a la mejor película extranjera (1988), como ejemplo de entrega gratuita y gozosa. Por ultimo, el documento cita a personajes conocidos por la sociedad contemporánea: Martín Luther King (n. 118), Erich Fromm (n. 284), Dietrich Bonhoeffer (n. 320) y un verso de la poesía Te quiero de Mario Benedetti (n. 181).

\subsection{Un documento pastoral}

A lo largo de la exhortación se comprende la familia como una institución en crisis, pero, a la vez, totalmente vigente y apreciada. Además, junto con ofrecer el ideal cristiano de la familia, se toma en cuenta su realidad concreta, es decir, con "los pies en la tierra"; en esta dimensión humana también se aplica el principio conciliar de los signos de los tiempos (AL, n. 31 y 77).

Es sano prestar atención a la realidad concreta, porque las exigencias y llamadas del Espíritu Santo resuenan también en los acontecimientos mismos de la historia, a través de los cuales la Iglesia puede ser guiada a una comprensión más profunda del inagotable misterio del matrimonio y de la familia (n. 31).

Por ello, el tono del documento es pastoral más que doctrinal. Se ofrece y se recuerda la enseñanza de la Iglesia sobre el matrimonio y la familia, pero, a la vez, se insiste y se orienta en la acogida y el acompañamiento en las situaciones concretas para caminar hacia este ideal o para vivir lo mejor posible las circunstancias reales. 
La oferta de la propuesta cristiana tiene la responsabilidad de presentar las razones y las motivaciones para optar por el matrimonio y la familia. Al respecto, se hace una autocrítica. "Tenemos que ser humildes y realistas, para reconocer que a veces nuestro modo de presentar las convicciones cristianas, y la forma de tratar a las personas, han ayudado a provocar lo que hoy lamentamos, por lo cual nos corresponde una saludable reacción de autocrítica" (AL, n. 36). Otras veces, se ha presentado "un ideal teológico del matrimonio demasiado abstracto, casi artificiosamente construido, lejano de la situación concreta y de las posibilidades efectivas de las familias reales" (AL, n. 36).

Por consiguiente, no es suficiente insistir tan sólo "en cuestiones doctrinales, bioéticas y morales, sin motivar la apertura a la gracia" (AL, n. 37), porque la realidad de la familia es un camino a recorrer. Tampoco se ha dado la debida importancia a la conciencia de los fieles, "que muchas veces responden lo mejor posible al Evangelio en medio de sus límites y pueden desarrollar su propio discernimiento ante situaciones donde se rompen todos los esquemas" (AL, n. 37). No hay que olvidar que "estamos llamados a formar las conciencias, pero no a pretender sustituirlas" (AL, n. 37).

\subsection{Unidad y pluralidad}

Por último, el Papa Francisco expresa su convicción de que "no todas las discusiones doctrinales, morales o pastorales deben ser resueltas con intervenciones magisteriales". Obviamente, resulta indispensable una unidad de doctrina y práctica. Pero la realidad permite diferentes maneras de "interpretar algunos aspectos de la doctrina o algunas consecuencias que se derivan de ella", "hasta que el Espíritu nos lleve a la verdad completa (AL, n. 16,13)". Por ello, "en cada país o región se pueden buscar soluciones más inculturadas, atentas a las tradiciones y a los desafíos locales, porque "las culturas son muy diferentes entre sí y todo principio general [...] necesita ser inculturado si quiere ser observado y aplicado" (AL, n. 3).

En otras palabras, unidad de doctrina pero pluralidad en su expresión para poder ser fiel a su único significado. La pluralidad de expresión, a través de las distintas culturas, asegura un significado relevante y comprensible universal en los distintas lugares. De otra manera, se impondrá una cultura sobre otra y se tiene uniformidad mediante una colonización de una cultura sobre otras. Así que es preciso que haya un significado transmitido en una pluralidad de expresiones para que sea de verdad universal: un contenido y sus distintas expresiones.

\section{Las primeras reacciones}

El día 8 de abril de 2016 le tocó al Cardenal Christoph Schönborn presentar oficialmente el texto de la exhortación. Sus primeras palabras subrayan 
que se trata de un texto pontificio comprensible, porque no recurre a un lenguaje académico, sino que hace referencia a la experiencia cotidiana. Es que "los documentos de la Iglesia a menudo no pertenecen a un género literario de los más asequibles"; sin embargo "este texto del Papa es legible". Aún más, "el Papa Francisco habla de las familias con una claridad que pocas veces se encuentra en los documentos del magisterio de la Iglesia". ${ }^{1}$

\subsection{Presentación}

El Cardenal Schönborn procede a destacar que la exhortación conoce todas las situaciones del matrimonio en el mundo actual. "El Papa Francisco ha conseguido hablar de todas las situaciones sin catalogar, sin categorizar, con esa mirada fundamental de benevolencia que tiene algo que ver con el corazón de Dios, con los ojos de Jesús, que no excluyen a nadie (AL, n. 297), que acogen a todos" (2016). Así, "nadie debe sentirse condenado, nadie despreciado", porque "la enseñanza de la visión cristiana del matrimonio y de la familia, se convierte en invitación, estímulo, alegría del amor en la que podemos creer y que no excluye, verdadera y sinceramente, a nadie" (2016).

En la exhortación queda muy claro, subraya el purpurado, que el Papa Francisco sostiene la doctrina tradicional de la Iglesia sobre el matrimonio. "Los cristianos no podemos renunciar a proponer el matrimonio con el fin de no contradecir la sensibilidad actual, para estar a la moda, o por sentimientos de inferioridad frente al descalabro moral y humano" (SCHÖNBORN, 2016). Por ello, cabe destacar la responsabilidad de "presentar las razones y las motivaciones para optar por el matrimonio y la familia, de manera que las personas estén mejor dispuestas a responder a la gracia que Dios les ofrece" (AL, n. 35).

Así, en esta presentación se deja en claro que los capítulos 4 y 5 da AL (El amor en el matrimonio y Amor que se vuelve fecundo) son centrales en la exhortación, porque pretenden estimular "el crecimiento, la consolidación y la profundización del amor conyugal y familiar" (n. 89). El capítulo 4 es una profunda reflexión a partir del Himno de la caridad del capítulo 13 de la primera Carta a los Corintios. "Recomiendo a todos", insiste el Cardenal, "la meditación de estas páginas". Sin embargo, el presentador está muy consciente de que estos dos capítulos centrales de Amoris laetitia "serán probablemente saltados por muchos para arribar inmediatamente a las 'papas calientes', a los puntos críticos" (SCHÖNBORN, 2016)

Obviamente, será el octavo capítulo (Acompañar, discernir e integrar la fragilidad) él que llamará más la atención al público mundial, porque "la cuestión de cómo la Iglesia trate estas heridas, de cómo trate los fracasos del amor se ha vuelto para muchos una cuestión-test para entender si la

\footnotetext{
${ }^{1}$ SCHÖNBORN, C. Presentación de la exhortación apostólica post-sinodal Amoris Laetitia: la lógica de la misericordia pastoral, 08.04.2016. Disponible en: https://press.vatican.va/content/ salastampa/es/bollettino/pubblico/2016/04/08/presentacion.html.
} 
Iglesia es verdaderamente el lugar en el cual se puede experimentar la misericordia de Dios" (SCHÖNBORN, 2016).

El Papa Francisco hace suyas las declaraciones de ambos Sínodos (AL, n. 297) y en lo que respecta a los divorciados vueltos a casar con rito civil sostiene que "la lógica de la integración es la clave de su acompañamiento pastoral" (AL, n. 299). Por tanto, no deberían sentirse excomulgados de la Iglesia, sino más bien ser miembros vivos de ella, sintiéndola como "una madre que les acoge siempre" (AL, n. 299).

Pero, se pregunta el Cardenal Schönborn, ¿qué significa esto concretamente? La respuesta decisiva, contesta, está en el párrafo 300. Las diferentes y variadas situaciones concretas impiden una nueva normativa general de tipo canónica, aplicable a todos los casos. Por tanto, sólo cabe un responsable discernimiento personal y pastoral de los casos particulares; un discernimiento que "no podrá jamás prescindir de las exigencias de verdad y de caridad del Evangelio propuesto por la Iglesia" (AL, n. 300). Por consiguiente, "el Papa afirma, de manera humilde y simple, en una nota (n. 351), que se puede dar también la ayuda de los sacramentos en caso de situaciones 'irregulares'”' (2016).

En la conferencia de prensa del Papa Francisco a bordo del avión de vuelta a Roma desde Lesbo (Grecia), el día 16 de abril del año 2016, el periodista Francis Rocca del Wall Street Journal pregunta si ha cambiado la postura oficial de la Iglesia con respecto al acceso a los sacramentos de los divorciados vueltos a casar. El Pontífice contesta:

Podría decir sí, y punto. Pero sería una respuesta demasiado pequeña. Les recomiendo leer la presentación que hizo el Cardenal Schönborn, quien es un grande teólogo. Él es miembro de la Congregación para la Doctrina de la Fe y conoce bien la doctrina de la Iglesia. En aquella presentación está la respuesta a su pregunta. ${ }^{2}$

El día 5 de septiembre de 2016, los Obispos de la región pastoral de Buenos Aires publican una Declaración sobre Criterios básicos para la aplicación del capitulo VIII de Amoris laetitia.

Si se llega a reconocer que, en un caso concreto, hay limitaciones que atenúan la responsabilidad y la culpabilidad (n. 301-302), particularmente cuando una persona considere que caería en una ulterior falta dañando a los hijos de la nueva unión, Amoris laetitia abre la posibilidad del acceso a los sacramentos de la Reconciliación y la Eucaristía (notas 336 y 351). Estos a su vez disponen a la persona a seguir madurando y creciendo con la fuerza de la gracia. ${ }^{3}$

\footnotetext{
${ }^{2}$ FRANCISCO, Papa. Visita del santo padre francisco a lesbos (Grecia). Conferencia de prensa del Santo Padre durante el vuelo de regreso a Roma. Roma: 2016b. Disponible en: http://www. vatican.va/content/francesco/es/speeches/2016/april/documents/papa-francesco_20160416_lesvos-volo-ritorno.html.

${ }^{3}$ OBISPOS DE LA REGIÓN BUENOS AIRES. Criterios básicos para la aplicación del capítulo VIII de Amoris laetitia, Roma: 2016. Medellín, Bogotá, v. 42, n. 165, 2016. Disponible en: http:// documental.celam.org/medellin/index.php/medellin/article/view/153.
} 
El mismo día, desde el Vaticano, el Papa Francisco envía una carta de respuesta a estos Obispos, en la cual les dice: "El escrito es muy bueno y explícita cabalmente el sentido del capítulo VIII de Amoris laetitia. No hay otras interpretaciones". ${ }^{4}$ Además les recuerda que "Amoris laetitia fue el fruto del trabajo y la oración de toda la Iglesia, con la mediación de dos Sínodos y del Papa".

\subsection{Conferencias Episcopales}

Algunas Conferencias Episcopales salieron a apoyar públicamente la exhortación apostólica del Papa Francisco. La Conferencia Episcopal Alemana habló del "gran obsequio" que el Papa hizo a la Iglesia, reconociendo también la gran contribución del "camino sinodal" en el proceso de la exhortación. "La indisolubilidad del matrimonio es parte del depósito esencial de la fe de la Iglesia", declaran los obispos alemanes. "Amoris laetitia es categórica a este respecto, como también en lo referente a la necesidad de considerar de manera diferenciada las respectivas situaciones de vida de las personas".

Otra declaración muy notable fue la carta pastoral Mirada de Dios sobre la vida (en japonés, Inochi he no manazashi), publicada al comienzo de Cuaresma de 2017 por el episcopado japonés, que la firmó por total unanimidad el 1 de enero de 2017, Jornada mundial por la paz (MASIÁ, 2017). Su preocupación pastoral como obispos les lleva a afirmar:

Nosotros tenemos que reconocer, arrepintiéndonos, que la iglesia se ha venido comportando hasta hace poco más bien como juez que como madre, por lo que se refiere a las personas que no han podido salvar su matrimonio. Pero hoy pensamos que se debe acoger y abrazar cálidamente, como hizo Jesucristo, el sufrimiento de las personas, y que debemos apoyarlas y animarlas, acompañándolas en el camino para rehacer de nuevo su vida. (n. 34, p. 61 del texto oficial japonés). ${ }^{5}$

\subsection{Distracción y oposición}

Sin embargo, también hubo oposición, que el mismo Papa Francisco previó cuando afirma en la misma exhortación que "comprendo a quienes prefieren una pastoral más rígida que no dé lugar a confusión alguna" (AL, n. 308). No obstante, tiene la convicción evangélica de que "Jesucristo quiere una Iglesia atenta al bien que el Espíritu derrama en medio de la

\footnotetext{
${ }^{4}$ FRANCISCO, Papa. Carta del Santo Padre Francisco a los Obispos de la región pastoral de Buenos Aires en respuesta al documento "criterios básicos para la aplicación del capítulo viii de la amoris laetitia". Roma 2016c. Disponible en: http://www.vatican.va/content/francesco/es/letters/2016/ documents/papa-francesco_20160905_regione-pastorale-buenos-aires.html.

${ }^{5}$ MASIÁ, J. Los obispos japoneses, con Amoris laetitia, antes y después. Religión Digital, 14 de marzo de 2017. Disponible en: https://www.religiondigital.org/opinion/Juan-Masiajaponeses-Amoris-Laetitia_0_1884411600.html.
} 
fragilidad"; es decir, "que, al mismo tiempo que expresa claramente su enseñanza objetiva, no renuncia al bien posible, aunque corra el riesgo de mancharse con el barro del camino" (n. 308). Es la opciòn por "la lógica de la compasión con los frágiles y a evitar persecuciones o juicios demasiado duros o impacientes", porque "el mismo Evangelio nos reclama que no juzguemos ni condenemos (Mt 7, 1; Lc 6, 37)" (n. 308). Es que, termina afirmando el mismo Papa Francisco, "ponemos tantas condiciones a la misericordia que la vaciamos de sentido concreto y de significación real, y esa es la peor manera de licuar el Evangelio" (AL, n. 311).

La primera distracción vino de los medios de comunicación social. Por una parte, es de reconocer y agradecer que la exhortación apostólica estuvo en pauta por mucho tiempo, cubriendo también diariamente los dos Sínodos. Sin embargo, tendieron a reducir el camino sinodal a la pregunta por el acceso de los divorciados vueltos a casar por el civil a la comunión sacramental. Esto no era el tema sino un elemento que sólo se puede comprender correctamente a partir del marco más amplio del significado cristiano del matrimonio y de la familia.

El mismo Papa Francisco, en su viaje de vuelta desde Lebos (Grecia) a Roma (16 de abril de 2016), contesta al periodista Guénois del diario Le Figaro, que la gran preocupación de la mayoría de los medios fue sobre el acceso a la comunión de los divorciados vueltos a casar. Confesó que esta perspectiva le molestó y también le dio algo de tristeza.

Pienso: Pero ese medio que dice esto, esto, esto, ¿no se da cuenta de que ese no es el problema importante? ¿No te das cuenta de que la familia, en todo el mundo, está en crisis? ¡Y la familia es la base de la sociedad! ¿No notas que los jóvenes no quieren casarse? ¿No te das cuenta de que el descenso de la natalidad en Europa te hace llorar? ¿No se da cuenta de que la falta de trabajo y las posibilidades de trabajo hacen que el padre y la madre toman dos trabajos y los hijos crecen solos y no aprenden a crecer en diálogo con el padre y la madre? ¡Estos son los grandes problemas! ${ }^{6}$

Un segundo frente no ya de distracción sino de franca oposición fue la carta de veinticinco páginas, firmada por 40 clérigos católicos y académicos laicos, enviada al Papa Francisco el 11 de agosto de 2017. La declaración se tituló Correctio filialis de haeresibus propagatis (una corrección filial con respecto a la propagación de herejías). Como no se recibió respuesta de parte del Papa Francisco, la carta se hizo pública el día 24 de septiembre del años $2017^{7}$.

\footnotetext{
${ }^{6}$ FRANCISCO, Papa. Visita del santo padre Francisco a Lesbos (Grecia). Conferencia de prensa del Santo Padre durante el vuelo de regreso a Roma. Roma: 2016b. Disponible en: http://www.vatican. va/content/francesco/es/speeches/2016/april/documents/papa-francesco_20160416_lesvos-voloritorno.html.

7 CORRECTIO FILIALIS DE HAERESIBUS PROPAGATIS. 16 de julio de 2017. Disponible en: http://www.correctiofilialis.org/wp-content/uploads/2017/08/Correctio-filialis_ Espan\%CC\%83ol_1.pdf.
} 
En la carta enviada al Papa, se afirma que la AL, como también debido a otras palabras, actos y omisiones que se le relacionan, el Pontífice "ha sostenido siete posturas heréticas en referencia al matrimonio, la vida moral y la recepción de los sacramentos, y ha provocado que estas opiniones heréticas se propaguen en la Iglesia Católica". (2017)

El 19 de septiembre de 2016, cuatro cardenales (Raymond Burke, Carlo Cafarra, Walter Brandmüller y Joachim Meisner) solicitaron una aclaración (dubia) sobre cinco puntos al Papa Francisco sobre AL. Al no recibir una respuesta, publicaron la carta titulada La búsqueda de la claridad: una súplica para desatar los nudos en Amoris laetitia, en la cual sostienen que partes del documento contienen ambigüedades y declaraciones que son como nudos que no pueden ser fácilmente desatados y están causando gran confusión. En el fondo, critican el capítulo ocho de la exhortación porque genera confusión y desconcierto.

Mons. Víctor Manuel Fernández resume en un párrafo lúcido este periodo agitado de reacciones adversas a la exhortación apostólica. "Después de varios meses de intensa actividad de los sectores que se oponen a las novedades del capítulo octavo de Amoris Laetitia - minoritarios pero hiperactivos - o de fuertes intentos para disimularlas, la guerra parece haber llegado a un punto muerto" (FERNÁNDEZ, 2017, p. 451).

\section{Unos acentos pastorales}

Amoris laetitia no presenta ninguna doctrina nueva; aún más, el carácter de indisolubilidad del sacramento del matrimonio se reitera una y otra vez a lo largo del documento (AL, n. 29, 52, 62, 66, 86, 122, 123, 124, 159, $162,178,218,292)$.

No hay ninguna novedad doctrinal, pero se asume una perspectiva capaz de asumir la fragilidad humana y guiarla hacia el camino del ideal cristiano, subrayando la primacía de la conciencia de las personas. En otras palabras, trata al cristiano como un adulto, consciente de las dificultades que entraña la realidad concreta y confiando en su sentido de responsabilidad, fruto de su vida espiritual y mediante el discernimiento.

En sentido estricto, la posibilidad de acceso a la comunión de las personas divorciadas y vueltas a casar, acorde a un discernimiento en conciencia, no constituye una novedad porque la Iglesia siempre ha mantenido el principio de la primacía de la conciencia (CIC, n. 1776 - 1782). La novedad está más bien en que lo que antes se prohibía ahora no lo está. En otras palabras, la afirmación de que "la Iglesia, fundándose en la Sagrada Escritura reafirma su praxis de no admitir a la comunión eucarística a los 
divorciados que se casan otra vez" (FC, n. 84), ha sido reemplazada por la que la misma Familiaris consortio establece en el mismo párrafo citado, al sostener la obligación "de discernir bien las situaciones" (n. 84). "La teología de la Familiaris consorcio", escribe Austen Iveriegh, "se lleva a cabo a nivel de lo sacramental y objetivo, mientras que Amoris laetitia, reflejando lo del sínodo, es esencialmente pastoral y personal" (2017).

Es preciso no confundir doctrina y disciplina. El teólogo dominico Giovanni Cavalcoli aclara que "conceder o no conceder la comunión entra en el poder de la pastoral de la Iglesia y en las normas de la liturgia, establecidas por la Iglesia según su prudencia". Lo importante es "evitar tanto la rigidez de un conservadurismo rigorista" como el "modernismo historicista y laxo" (CAVALCOLI, 2015).

El tema del acceso a la comunión de los divorciados vueltos a casar pertenece al ámbito de la disciplina y no de la doctrina. La ley eclesiástica pretende ordenar la práctica concreta de una ley divina. Es decir, establecer las circunstancias, las condiciones, la forma, el lugar, el tiempo, a quién administrar los sacramentos es responsabilidad de la Iglesia.

A lo largo de la historia de la Iglesia ha habido cambios en la disciplina de los sacramentos. A título de ejemplo, ciertamente no exhaustivo, se puede señalar: (a) en el sacramento de la reconciliación, la Iglesia pasó de la praxis de los primeros siglos de una sola celebración durante toda la vida a la recomendación actual de la confesión frecuente; (b) en los primeros siglos las segundas nupcias eran desaconsejadas; (c) hasta la reforma conciliar, el sacramento de la unción de los enfermos, llamado en ese entonces "extrema unción", era administrado sólo a los moribundos, mientras en la actualidad se puede administrar varias veces en situaciones de ancianidad y enfermedad grave. (CAVALCOLI, 2015).

La Iglesia va creciendo y profundizando en el tiempo en la comprensión del Evangelio, sea en tener una visión más completa como también en nuevos y distintos modos de aplicar lo enseñado debido a los nuevos contextos que van surgiendo en la historia de la humanidad. ${ }^{8}$

\footnotetext{
${ }^{8}$ Mons. Víctor Manuel Fernández presenta distintos cambios disciplinares en la historia de la Iglesia. "En 1832 el Papa Gregorio XVI, en Mirari vos, había dicho que es una "absurda y errónea sentencia, o más bien delirio, que se deba admitir y garantizar a cualquiera la libertad de conciencia" (MV, n. 15). En el Syllabus de Pío IX (1864) la libertad religiosa se condena como uno de los principales "errores". Pero en el siglo siguiente, el Concilio Vaticano II modificó sustancialmente estas ideas tan firmes (DH, n 2-3). Una evolución semejante se dio en el tema de la posibilidad de salvación fuera de la Iglesia Católica. Recordemos también el caso de la esclavitud: el Papa Nicolás V permitió al rey de Portugal tomar esclavos. Luego, la Bula Romanus Pontifex (10.13), de 1455, lo reafirmó. Y no se trata de un tema secundario, puesto que tiene que ver con la inalienable dignidad de la persona humana. A partir de estos cambios en la comprensión de la doctrina, hubo, como consecuencia, diversos cambios en la disciplina.
} 


\subsection{Evolución más que ruptura}

En los casos de los divorciados vueltos a casarse civilmente, la práctica oficial de la pastoral fue la de "vivir como hermanos". Así, Juan Pablo II, en su exhortación apostólica FC, recordaba en el párrafo 84:

La reconciliación en el sacramento de la penitencia - que les abriría el camino al sacramento eucarístico - puede darse únicamente a los que, arrepentidos de haber violado el signo de la Alianza y de la fidelidad a Cristo, están dispuestos a una forma de vida que no contradiga la indisolubilidad del matrimonio. Esto lleva consigo concretamente que cuando el hombre y la mujer, por motivos serios, - como, por ejemplo, la educación de los hijos - no pueden cumplir la obligación de la separación, 'asumen el compromiso de vivir en plena continencia, o sea de abstenerse de los actos propios de los esposos'.

Posteriormente, Benedicto XVI, en su exhortación apostólica postsinodal Sacramentum caritatis, en el párrafo 29, evita la palabra asumir, cambiándola por anima a esforzarse.

Cuando no se reconoce la nulidad del vínculo matrimonial y se dan las condiciones objetivas que hacen la convivencia irreversible de hecho, la Iglesia anima a estos fieles a esforzarse por vivir su relación según las exigencias de la ley de Dios, como amigos, como hermano y hermana; así podrán acercarse a la mesa eucarística, según las disposiciones previstas por la praxis eclesial. (2007)

Por último, el Papa Francisco en su exhortación apostólica postsinodal AL, en su párrafo 303, plantea el proceso del discernimiento de una conciencia formada.

A partir del reconocimiento del peso de los condicionamientos concretos, podemos agregar que la conciencia de las personas debe ser mejor incorporada en la praxis de la Iglesia en algunas situaciones que no realizan objetivamente nuestra concepción del matrimonio. Ciertamente, que hay que alentar la maduración de una conciencia iluminada, formada y acompañada por el discernimiento responsable y serio del pastor, y proponer una confianza cada vez mayor en la gracia. Pero esa conciencia puede reconocer no sólo que una situación no responde objetivamente a la propuesta general del Evangelio. También puede reconocer con sinceridad y honestidad aquello que, por ahora, es la respuesta generosa que se puede ofrecer a Dios, y descubrir con cierta seguridad moral que esa es la entrega que Dios mismo está reclamando en medio de la complejidad concreta de los límites, aunque todavía no sea plenamente el ideal objetivo. De todos modos, recordemos que este discernimiento es dinámico y debe permanecer siempre abierto a nuevas etapas de crecimiento y a nuevas decisiones que permitan realizar el ideal de manera más plena. (2016a)

Por consiguiente, la práctica pastoral de recurrir a la continencia, de vivir como hermanos, en el caso de los divorciados vueltos a casar civilmente, ha pasado de la obligación de asumir, pasando a un animar a esforzarse, terminando con la apelación a un trabajo de discernimiento por parte de los involucrados. 
Algo similar pasa con el tema del acceso a la comunión de los divorciados vueltos a casar civilmente. Juan Pablo II, en su exhortación apostólica FC, en su párrafo 84, insistió en la obligación de "discernir bien las situaciones", porque "hay diferencia entre los que sinceramente se han esforzado por salvar el primer matrimonio y han sido abandonados del todo injustamente, y los que por culpa grave han destruido un matrimonio canónicamente válido". Además, se encuentran aquellos "que han contraído una segunda unión en vista a la educación de los hijos, y a veces están subjetivamente seguros en conciencia de que el precedente matrimonio, irreparablemente destruido, no había sido nunca válido".

Entonces, por una parte, pide "a los pastores y a toda la comunidad de los fieles para que ayuden a los divorciados, procurando con solícita caridad que no se consideren separados de la Iglesia, pudiendo y aun la Iglesia rece por ellos, los anime, se presente como madre misericordiosa y así los sostenga en la fe y en la esperanza" (FC, n. 84). Pero, acto seguido, afirma que "la Iglesia, no obstante, fundándose en la Sagrada Escritura reafirma su práxis de no admitir a la comunión eucarística a los divorciados que se casan otra vez".

En otras palabras, por una parte, se reconoce una variedad de situaciones distintas con mayor o menor responsabilidad, pero después se llega a una conclusión que desconoce totalmente la diversidad de las situaciones porque involucra a todas las situaciones por igual, sin diferenciar.

En AL se asume la diversidad de situaciones y se hace cargo y responsable de estas diferencias. El documento sostiene que no corresponde una nueva normativa general de tipo canónica, aplicable a todos los casos, porque las situaciones son muy diversas. Además, se reconoce, a la vez, que el grado de responsabilidad no es lo mismo en todos los casos, y, por tanto, las consecuencias y las aplicaciones de una norma no necesariamente tienen que ser siempre las mismas (n. 300).

En el caso de los divorciados vueltos a casar, observa el documento, existen situaciones muy diferentes, "que no han de ser catalogadas o encerradas en afirmaciones demasiado rígidas sin dejar lugar a un adecuado discernimiento personal y pastoral". Obviamente, este no es el ideal propuesto por el Evangelio, pero también es preciso distinguir las distintas situaciones y discernir adecuadamente porque "no existen recetas sencillas" (AL, n. 298).

La conclusión es la necesidad de "discernir cuáles de las diversas formas de exclusión actualmente practicadas en el ámbito litúrgico, pastoral, educativo e institucional pueden ser superadas". No se trata sólo de que no tienen que sentirse excomulgados, sino, más importante aún, la posibilidad de "vivir y madurar como miembros vivos de la Iglesia, sintiéndola como una madre que les acoge siempre, los cuida con afecto y los anima en el camino de la vida y del Evangelio" (AL, n. 299). 


\subsection{Crecimiento en la fe}

El ethos cristiano se fundamenta en - y es consecuencia y coherencia con - la vida espiritual. Es decir, la espiritualidad (la experiencia de la fe) se hace y se traduce en un estilo de vida consecuente y coherente (el compromiso del ethos). Este tema clave en la comprensión correcta del ethos cristiano, explica por qué AL prefiere hablar del crecimiento de la fe, superando el lenguaje de la ley de gradualidad de la FC.

El documento recuerda la enseñanza contenida en la FC. La ley de gradualidad, propuesta por Juan Pablo II (n. 34), asume el ser humano en su proceso de crecimiento: "un ser histórico, que se construye día a día con sus opciones numerosas y libres". También las vidas de los esposos recorren un camino sostenidos "por el deseo sincero y activo de conocer cada vez mejor los valores que la ley divina tutela y promueve, y por la voluntad recta y generosa de encarnarlos en sus opciones concretas". Sin embargo, esto no significa considerar a la ley "como un mero ideal que se puede alcanzar en el futuro, sino que deben considerarla como un mandato de Cristo Señor a superar con valentía las dificultades". Así, Juan Pablo II deja en claro que "la ley de gradualidad" (o camino gradual) no puede identificarse con la "gradualidad de la ley", "como si hubiera varios grados o formas de precepto en la ley divina para los diversos hombres y situaciones".

La misión de la Iglesia no consiste en condenar, sino en difundir la misericordia a todas aquellas personas que la piden con corazón sincero. Por ello, el Papa Francisco afirma que "nadie puede ser condenado para siempre, porque esa no es la lógica del Evangelio" (AL, n. 297). Entonces, "hay que evitar los juicios que no toman en cuenta la complejidad de las diversas situaciones, y hay que estar atentos al modo en que las personas viven y sufren a causa de su condición" (AL, n. 296). Es la lógica evangélica de la integración a la comunidad (IVEREIGH, 2017).

En el documento queda claro que la ley de gradualidad se entiende más bien en términos de la ley de crecimiento. Ya anteriormente, en su exhortaciòn apostólica Evangelii gaudium sobre el anuncia del Evangelio en el mundo actual (2013), el Pontífice había sostenido que, sin descartar ni disminuir el valor del ideal evangélico, "hay que acompañar con misericordia y paciencia las etapas posibles de crecimiento de las personas que se van construyendo día a día". En este caso, un pequeño paso, en medio de grandes límites humanos, puede ser más agradable a Dios que la vida exteriormente correcta de quien transcurre sus días sin enfrentar importantes dificultades" (n. 44).

Este cambio de acento coloca el punto de referencia no en la ley sino en el ideal evangélico. La gradualidad supone la coincidencia con la ley. La referencia al ideal evangélico hace referencia a la idea de crecimiento. Es decir, 
la ley no es ya el único parámetro para valorar el progreso de la persona en el camino del bien. En este sentido, sería más adecuado hablar de ley del crecimiento que de ley de la gradualidad.

Dado que en la misma ley no hay gradualidad (FC, n. 34), el documento AL recuerda que "este discernimiento no podrá jamás prescindir de las exigencias de verdad y de caridad del Evangelio propuesto por la Iglesia". Así, se presupone que "deben garantizarse las condiciones necesarias de humildad, reserva, amor a la Iglesia y a su enseñanza, en la búsqueda sincera de la voluntad de Dios y con el deseo de alcanzar una respuesta a ella más perfecta" (n. 300).

Así, el discernimiento pastoral no se reduce a considerar si una acción personal está conforme con una ley o norma general. Las normas tienen un papel orientador, $\mathrm{y}$, por tanto, necesario, pero "en su formulación no pueden abarcar absolutamente todas las situaciones particulares" ( $\mathrm{AL}, \mathrm{n}$. 304).

En otras palabras, escribe el Papa Francisco, "el discernimiento debe ayudar a encontrar los posibles caminos de respuesta a Dios y de crecimiento en medio de los límites. Por creer que todo es blanco o negro a veces cerramos el camino de la gracia y del crecimiento, y desalentamos caminos de santificación que dan gloria a Dios" (AL, n. 305).

De hecho, en el pensamiento moral siempre se ha insistido en la importancia y la relevancia de las circunstancias atenuentas a la hora de raealizar un juicio. El mismo CIC lo expresa en los siguientes términos: "La imputabilidad y la responsabilidad de una acción pueden quedar disminuidas e incluso suprimidas a causa de la ignorancia, la inadvertencia, la violencia, el temor, los hábitos, los afectos desordenados y otros factores psíquicos o sociales" (n. 1735). Por tanto, un juicio negativo sobre una situación objetiva no implica necesariamente un juicio sobre la imputabilidad o la culpabilidad de la persona involucrada.

Esta consideración significa que el reconocimiento de los condicionamientos implica que, en términos del Papa Francisco, "la conciencia de las personas debe ser mejor incorporada en la praxis de la Iglesia en algunas situaciones que no realizan objetivamente nuestra concepción del matrimonio" (AL, n. 303).

\subsection{El camino hacia lo ideal}

En la elaboración del discurso ético es esencial mantener una relación complementaria entre lo ideal y lo real. Por una parte, si la ética no toma en cuenta la realidad concreta podría terminar siendo una palabra irrelevante e inútil; por otra parte, en la ausencia de un ideal no existe una motivación ni un motor para cambiar la realidad hacia mayores cuotas de humanidad. 
Por consiguiente, resulta clave colocar el ideal como meta y punto de llegada porque su colocación como punto de partida ha hecho mucho daño, ya que cualquier persona honesta reconoce que uno va creciendo durante el curso de toda una vida, en términos teológicos diríamos la constante conversión. El ideal como punto de partida es una experiencia de fracaso y culpabilidad; el ideal como punto de llegada es una motivación de seguir superándose desde su situación concreta. En este segundo caso, el desafío ético abarca a todos y cada uno, mientras el ideal como punto de partida implicaría la marginación de aquellos que no lo cumplen.

En la actualidad, las situaciones matrimoniales son bien diversas. El mundo ha cambiado. "Amoris laetitia, fruto de un sínodo que pasó mucho tiempo examinando el mundo tal como es ahora, tiene un enfoque diferente. El divorcio ya no es un lobo rondando 'por ahí', de la que se debe defender el rebaño; está dentro del redil, devastando el rebaño" (IVEREIGH, 2017).

Esta perspectiva está presente en Amoris laetitia. "Cada matrimonio es una historia de salvación, y esto supone que se parte de una fragilidad que, gracias al don de Dios y a una respuesta creativa y generosa, va dando paso a una realidad cada vez más sólida y preciosa" (n. 221).

"Ninguna familia es una realidad celestial, (...) sino que requiere una progresiva maduración de su capacidad de amar". La perfección sólo se encontrará en el Reino definitivo del Padre" (AL, n. 325). "Somos personas y realidades familiares", escribe Carmen Reyes, "que están siempre en proceso de transformación, de maduración, incompletas e inacabadas, en camino hacia una perfección que no es exigible en esta vida. Las personas somos limitadas (AL, n. 122), avanzamos paso a paso" (REYES, 2017). ${ }^{9}$

Justamente, en la autocrítica realizada por Francisco, se menciona un idealismo ingenuo que desconoce la realidad, cuando "hemos presentado un ideal teológico del matrimonio demasiado abstracto, casi artificiosamente construido, lejano de la situación concreta y de las posibilidades efectivas de las familias reales" (AL, n. 36). Esta idealización excesiva asusta a las personas, que, a su vez, piensan que la Iglesia no entiende bien la vida matrimonial.

También la falta de un sentido de la realidad puede provocar profundas frustraciones en la vida matrimonial.

Una de las causas que llevan a rupturas matrimoniales es tener expectativas demasiado altas sobre la vida conyugal. Cuando se descubre la realidad, más

\footnotetext{
${ }^{9}$ En Amoris laetitia se recuerda: "Aunque 'la analogía entre la pareja marido-mujer y CristoIglesia' es una 'analogía imperfecta', invita a invocar al Señor para que derrame su propio amor en los límites de las relaciones conyugales" (n. 73).
} 
limitada y desafiante que lo que se había soñado, la solución no es pensar rápida e irresponsablemente en la separación, sino asumir el matrimonio como un camino de maduración (AL, n. 221).

No se trata de debilitar ni ocultar el ideal de un matrimonio cristiano. "Para la comunidad cristiana, hacerse cargo de ellos no implica un debilitamiento de su fe y de su testimonio acerca de la indisolubilidad matrimonial, es más, en ese cuidado expresa precisamente su caridad" (AL, n. 243). Porque, explica el documento, "comprender las situaciones excepcionales nunca implica ocultar la luz del ideal más pleno ni proponer menos que lo que Jesús ofrece al ser humano" (AL, n. 307).

De hecho, se ha criticado que la Iglesia, en este tema, no ha sido un "claro reflejo de la predicación y de las actitudes de Jesús que, al mismo tiempo que proponía un ideal exigente, nunca perdía la cercanía compasiva con los frágiles, como la samaritana o la mujer adúltera" (AL, n. 38).

El Papa Francisco expresa su convicción que "la misericordia del Señor" siempre "nos estimula a hacer el bien posible":

Creo sinceramente que Jesucristo quiere una Iglesia atenta al bien que el Espíritu derrama en medio de la fragilidad: una Madre que, al mismo tiempo que expresa claramente su enseñanza objetiva, no renuncia al bien posible, aunque corra el riesgo de mancharse con el barro del camino... El mismo Evangelio nos reclama que no juzguemos ni condenemos (Mt 7,1; Lc 6,37) (AL, n. 308).

\section{Un ethos de acompañamiento}

El ethos que subyace a todo el documento de AL es una ética del discernimiento. Consciente de las dificultades y las distintas situaciones, mantiene en el horizonte el camino hacia lo ideal, pero, a la vez, pide un discernimiento de los casos concretos.

Por tanto, el Papa Francisco, acogiendo la propuesta sinodal, establece "un itinerario de acompañamiento y de discernimiento que orienta a estos fieles a la toma de conciencia de su situación ante Dios. La conversación con el sacerdote, en el fuero interno, contribuye a la formación de un juicio correcto sobre aquello que obstaculiza la posibilidad de una participación más plena en la vida de la Iglesia y sobre los pasos que pueden favorecerla y hacerla crecer" (AL, n. 300).

Esta afirmación presupone una eclesiología de integración, donde la pregunta clave no es quién puede pertenecer a la institución de la Iglesia, sino cómo ayudar a integrar las personas a ella. La Iglesia, recuerda el Pontífice, "no es una aduana, es la casa paterna donde hay lugar para cada uno con su vida a cuestas" (AL, n. 310). Esto significa 
que es preciso superar "una fría moral de escritorio al hablar sobre los temas más delicados, y nos sitúa más bien en el contexto de un discernimiento pastoral cargado de amor misericordioso, que siempre se inclina a comprender, a perdonar, a acompañar, a esperar, y sobre todo a integrar" (AL, n. 312).

Un ethos del discernimiento, cargado con una lógica de la misericordia pastoral, coloca el desafío y la tarea ética en una de acompañamiento respetuoso y motivador en el camino del crecimiento de la fe, que es la razón de ser de un ethos que pretende ser cristiana.

Sin embargo, todo esto quedará archivado en una biblioteca si no se crean los caminos institucionales en las diócesis para acompañar a las personas que desean discernir seriamente su situación particular e regreso a la comunidad eclesial.

\title{
Siglas
}

\author{
$\mathrm{AL}=$ Amoris laetitia \\ $\mathrm{CIC}=$ CATECISMO DE LA IGLESIA CATÓLICA \\ $\mathrm{FC}=$ Familiaris consorti
}

\section{Referencias}

BENEDICTO XVI, Papa. Exortação apostólica pós-sinodal Sacramentum caritatis [...] sobre a eucaristia fonte e ápice da vida e da missão da igreja. Roma: 2007. Disponible en: http://www.vatican.va/content/benedict-xvi/pt/apost_exhortations/documents/ hf_ben-xvi_exh_20070222_sacramentum-caritatis.html.

CATECISMO DE LA IGLESIA CATÓLICA. Completo y acualizado. Città del Vaticano: Vaticana, 1997.

CAVALCOLI, G. La comunión a los divorciados vueltos a casar no toca la doctrina, sino la disciplina, Vatican Insider, 17 de octubre de 2015. Disponible en: http:// peregrinos-robertoyruth.blogspot.com/2015/10/la-comunion-los-divorciados-vueltos. html. Acceso en: 19 sept. 2020.

CONFERENCIA EPISCOPAL ALEMANA. La alegría del amor que se vive en las familias es también el júbilo de la Iglesia, 1 de febrero de 2017.

CORRECTIO FILIALIS DE HAERESIBUS PROPAGATIS. 16 de julio de 2017. Disponible en: http://www.correctiofilialis.org/wp-content/uploads/2017/08/Correctiofilialis_Espan\%CC\%83ol_1.pdf.

FERNÁNDEZ, V. M. El capítulo VIII de Amoris laetitia: lo que queda después de la tormenta. Medellín,, Bogotá, v. 43, n. 168, p. 449-468, mayo-agosto 2017. 
FRANCISCO, Papa. Exhortación apostólica Evangelii gaudium [...] sobre el anuncio del evangelio en el mundo actual Roma: 2013. Disponible en: http://www.vatican.va/ content/francesco/es/apost_exhortations/documents/papa-francesco_esortazioneap_20131124_evangelii-gaudium.html 24 de noviembre de 2013.

FRANCISCO, Papa. Exhortación apostólica postsinodal Amoris Laetitia [...] sobre el amor en la familia. Roma: 2016a. Disponible en: http://www.vatican.va/content/francesco/ es/apost_exhortations/documents/papa-francesco_esortazione-ap_20160319_amorislaetitia.html.

FRANCISCO, Papa. Visita del Santo padre Francisco a Lesbos (Grecia). Conferencia de prensa del Santo Padre durante el vuelo de regreso a Roma. Roma: 2016b. Disponible en: http://www.vatican.va/content/francesco/es/speeches/2016/april/ documents/papa-francesco_20160416_lesvos-volo-ritorno.html.

FRANCISCO, Papa. Carta del Santo Padre Francisco a los Obispos de la región pastoral de Buenos Aires en respuesta al documento "criterios básicos para la aplicación del capítulo viii de la amoris laetitia". 2016c. Disponible en: http://www.vatican.va/content/ francesco/es/letters/2016/documents/papa-francesco_20160905_regione-pastorale-buenos-aires.html.

FRANCISCO, Papa. Discurso del Santo Padre Francisco a los miembros de la $36^{\underline{a}}$ Congregación General de la Compañía de Jesús. Aula de la Congregación General-Curia General de la Compañía de Jesús. 24 de octubre de 2016d. Disponible en: https:// www.educatemagis.org/wp-content/uploads/documents/2016/11/20161024_Discurso_Papa_CG36.pdf.

IVEREIGH, A. El problema real acerca de 'Amoris' es uno antiguo sobre la conciencia. Revista Cruz, 15 de enero de 2017.

JUAN PABLO II, Papa. Exhortación apostólica Familiaris Consortio sobre la misión de la familia Cristiana en el mundo actual. Roma: 1981. Disponible en: http://www.vatican. va/content/john-paul-ii/es/apost_exhortations/documents/hf_jp-ii_exh_19811122_familiaris-consortio.html.

MASIÁ, J. Los obispos japoneses, con Amoris laetitia, antes y después. Religión Digital, 14 de marzo de 2017. Disponible en: https://www.religiondigital.org/opinion/ Juan-Masia-japoneses-Amoris-Laetitia_0_1884411600.html.

MIFSUD, T. Ante las segundas nupcias: ¿Fidelidad y/o misericordia? Mensaje, Chile, v. 63, n. 635 , p. $23-25$, diciembre 2014.

MIFSUD, T. Iglesia: acoger a los divorciados vueltos a casar. Mensaje, Chile, v. 64, n. 642 , p. $14-18$, septiembre 2015.

MIFSUD, T. La alegría del amor. Mensaje, Chile, v. 65, n. 648, p. 6 -10, mayo 2016.

OBISPOS DE LA REGIÓN BUENOS AIRES. Criterios básicos para la aplicación del capítulo VIII de Amoris laetitia, 5 de septiembre de 2016. Medellín, Bogotá, v. 42, n. 165, 2016. Disponible en: http://documental.celam.org/medellin/index.php/ medellin/article/view/153.

REYES, C. El amor en el proceso de hacer familia, territorio abierto. Disponible en: jesuitas.cl/amor-proceso-familia/2017. Acceso en: 28 sept. 2020. 
SPADARO, A., "Amoris laetitia". Struttura e signficato dell'Esortazione apostolica post-sinodale di Papa Francesco, La Civiltà Cattolica, Roma, 3980, pp. 105 - 128, 23 april 2016.

SCHÖNBORN, C. Presentación de la exhortación apostólica post-sinodal Amoris Laetitia: la lógica de la misericordia pastoral, 08.04.2016. Disponible en: https://press. vatican.va/content/salastampa/es/bollettino/pubblico/2016/04/08/presentacion.html.

VIDAL, F. Fernando Vidal: fortalecer la familia para cambiar el mundo. Mensaje, Chile, p. 43 - 46, 07 junio, 2017. Entrevista realizada por J. Rauld.

Artículo sometido en 05.11.2020 y aprobado en 10.04.2021

Tony Mifsud s.j. es Doctor en Teología Moral, Universidad Católica de Comillas (Madrid, 1980) y Profesor del Departamento de Teología Universidad Católica del Norte - Antofagasta, Chile. Orcid.org/0000-0002-4653-3019. E-mail: tmifsudsj@gmail.com

Dirección: Av. Angamos 0610

Antofagasta, Chile 